\title{
The Conceptual Design of High Pressure Reversible Axial Tunnel Ventilation Fans
}

\author{
A. G. Sheard and K. Daneshkhah \\ Fläkt Woods Limited, Axial Way, Colchester, Essex CO4 5ZD, UK \\ Correspondence should be addressed to A. G. Sheard, geoff.sheard@flaktwoods.com
}

Received 22 September 2012; Accepted 12 November 2012

Academic Editor: Joseph C. S. Lai

Copyright ( $) 2012$ A. G. Sheard and K. Daneshkhah. This is an open access article distributed under the Creative Commons Attribution License, which permits unrestricted use, distribution, and reproduction in any medium, provided the original work is properly cited.

\begin{abstract}
Tunnel ventilation fans, classically, must have the ability to both supply and extract air from a tunnel system, with the operator's choice dependent on the tunnel ventilation system's operating mode most appropriate at any given point in time. Consequently, tunnel ventilation fans must incorporate a reversible aerodynamic design which limits the maximum fan pressure rise. This paper presents three high pressure reversible fan concepts. These comprise a two-stage counter rotating fan, a single-stage high speed fan, and a two-stage fan with a single motor and impeller on each end of the motor shaft. The authors consider the relative merits of each concept. The third concept offers the most compact fan, transform, silencer, and damper package size. The authors discuss the mechanical design challenges that occur with a two-stage fan with a single motor and impeller on each end of the motor shaft. They present and consider a selected motor bearing arrangement and casing design for maintainability. Finally, the authors present both prototype fan and full-scale package aerodynamic and acoustic performance, before discussing the challenges presented by high temperature certification in accordance with the requirements of EN 12101-3: 2012.
\end{abstract}

\section{Introduction}

The current limit on the pressure developing capability of single-stage reversible tunnel ventilation fan technology is $2000 \mathrm{~Pa}$. As tunnel length increases, the system resistance that occurs with a required flow can exceed this $2000 \mathrm{~Pa}$ limit. A second factor that escalates the required tunnel ventilation fan pressure developing capability is increasing train speeds in modern metro systems. Travelling in a tunnel, a train induces a positive pressure pulse ahead and a negative pressure pulse behind. When the train passes a ventilation shaft, a tunnel ventilation fan within the shaft first experiences a positive and then a negative pressure pulse.

Sheard and Corsini [1] considered pressure pulse magnitudes in tunnel ventilation systems and concluded that the historic norm is $300 \mathrm{~Pa}$. However, they identified a third factor which increases the required tunnel ventilation fan pressure development capability. The introduction of platform screen doors has increased the size of pressure pulses to typically $700 \mathrm{~Pa}$ and in combination with high train speeds as high as $1000 \mathrm{~Pa}$. Within the context of a historic system resistance of typically 1200 to $1500 \mathrm{~Pa}$, an increase in the pressure pulse magnitude from 300 to $700 \mathrm{~Pa}$ can take the total required pressure beyond the capability of a single reversible fan stage.

The above requirements imply a level of complexity in the design process that is beyond the historic norm within the fan industry. Empirical design methodological applications are no longer appropriate, with tunnel ventilation fan designers increasingly moving from empirical fan to industrial turbomachinery design methodologies. Wallis [2] and Daly [3] exemplify the traditional empirical approach to tunnel ventilation fan design and describe a trial-and-error approach that relies on the designer's experience.

More recently, tunnel ventilation fan designers have started to utilise computational fluid dynamics analyses at the beginning of the design process. Vad [4] and Corsini et al. [5] have proposed the application of computational methods in the fan design process. They have developed a family of high-performance swept fans for mine ventilation by 
feedingback the three-dimensional design criterion with computed aerodynamic data which provides insight into the size and nature of rotor secondary flows.

Lee et al. [6] recently applied an inverse approach to the design of cooling fans for electronic appliances. This included the combined use of a "design of experiments" step and computational fluid dynamics to explore the space available for design solutions. In doing so, Lee et al. [6] transferred methodologies that researchers had originally developed for turbomachinery to industrial fan design. Daneshkhah and Sheard [7] also utilised turbomachinery design methodologies. They developed an experimental design approach in combination with the use of computational fluid dynamics to optimise a tunnel ventilation jet fan blade's design. They based the design methodologies on Horlock and Denton's [8] design practices which are reliant on computational fluid dynamics to develop appropriate three dimensional blade sections.

Another issue of importance to the contemporary design of tunnel ventilation fans is that standards for the fans' acoustic performance during both routine and emergency operations have become progressively more stringent. During routine night-time operations, tunnel ventilation system noise at the exhaust portals is typically limited to $50 \mathrm{dBA}$ to avoid disturbing people who live in the vicinity. During emergency operations, operators typically limit noise to $85 \mathrm{dBA}$ to allow emergency services personnel to communicate effectively.

Borello et al. [9] studied the practicality of using an unsteady computational fluid dynamic code to assist in the assessment of tunnel ventilation fan acoustic characteristics. Borello et al. [9] concluded that more aggressive aerodynamic designs produce higher acoustic emissions, and consequently acoustic optimisation was an important aspect of a design methodology as aerodynamic and mechanical optimisation.

When responding to the constraints imposed upon them, tunnel ventilation fan designers require a methodology that provides an optimum balance between acoustic, aerodynamic, and mechanical requirements during both emergency operations at elevated temperature and during routine operation. In order to be effective, the tunnel ventilation fan designer must combine finite-element analysis (for mechanical analysis) and computational fluid dynamics (for aerodynamic and aeroacoustic analysis) to provide a virtual prototyping design methodology that replaces traditional test and evaluation methods in fan development.

Although virtual prototyping techniques are presently uncommon in the fan industry, other industries have used such techniques extensively. Pratt [10] and Jasnoch et al. [11] have studied virtual prototyping techniques. Both researchers independently concluded that they provide crossfunctional evaluations of competing objectives and enable issues that others have previously considered "downstream issues" during the initial design cycle stages. By developing virtual prototypes as "digital mockups", the process of virtual prototyping reduces the need to build physical prototypes and facilitates the early identification of design problems.
Sheard et al. [12] documented a case study of a virtual prototyping approach application in developing a new tunnel ventilation fan range. They used virtual prototypes to characterise the new generation tunnel ventilation fans' aerodynamic and aeroacoustic performance. Sheard et al.'s [12] work focused exclusively on single-stage fan development. The authors of this paper expanded this work and used it to design three tunnel ventilation fan concepts. These include a two-stage counter rotating fan, a high speed single-stage fan, and a two-stage fan with a single motor and impeller on each end of the motor shaft.

In this paper, the authors consider the mechanical challenges that occur with three tunnel ventilation fan concepts. They present the aerodynamic performance of the three fan concepts and discuss the mechanical design challenges. The paper then moves on to present the fan concept realisation that resulted in the most compact ventilation package: a two-stage fan with a single motor and impeller on each end of the motor shaft. Following a description of the realised design, the authors compare the laboratory performance of a prototype and first production fan, transform, silencer, and damper package to that which they predicted during the design process. The paper closes with a review of the challenges that may occur with high temperature certification of large tunnel ventilation fans in accordance with the requirements of EN 12101-3:2012. The authors provide conclusions and recommendations.

\section{Fan Design Requirements}

The reversible fan concepts presented in this paper were developed using the Marmaray project specification as an example of a "next-generation" tunnel ventilation system that requires a reversible fan beyond the current single-stage state of the art. Sheard et al. [13] described the Marmaray tunnel system design and observed that Parsons Brinckerhoff developed a specification for its tunnel ventilation fans, Table 1. The specification includes a minimum fan efficiency of $70 \%$. Although being modest by unidirectional fan standards, an efficiency of $70 \%$ is close to the state of the art for a conventional single-stage reversible fan, and therefore a specified efficiency of $70 \%$, and its associated power of $710 \mathrm{~kW}$ at the design flow and pressure, represents a challenge for tunnel ventilation fan designers.

The acoustic specification and requirement for $\mathrm{EN}$ 12101-3 certification also have an implication for the tunnel ventilation fans' pressure development capability. Any silencer has an associated pressure loss, so we must add this to the pressure that the fan generates. The Euro Norm EN 12101-3 requires tunnel ventilation fans to be capable of clearing smoke in the event of a tunnel fire. The clearance between aluminium blades and the steel casing within which they run must increase at ambient conditions to ensure that it does not close completely at elevated temperatures during a tunnel fire. Increasing blade tip-to-casing clearance reduces the tunnel ventilation fans' efficiency, as well as their pressure development capability.

The specification (Table 1) is for the fan, transform, damper, and silencer package and includes a $3400 \mathrm{~Pa}$ duty 
TABLE 1: Marmaray fan, transform, silencer, and damper package specification.

\begin{tabular}{lc}
\hline Pressure $(\mathrm{Pa})$ & 3400 \\
Pressure pulse $(\mathrm{Pa})$ & \pm 500 \\
Flow $\left(\mathrm{m}^{3} / \mathrm{s}\right)$ & 144 \\
Power $(\mathrm{kW})$ & 710 \\
Minimum efficiency $(\%)$ & 70 \\
dBA (tunnel side) & 85 ten metres from vent shaft \\
dBA (atmospheric side) & 85 ten metres from the vent shaft \\
EN 12101-3 certification & $250^{\circ} \mathrm{C}$ for one hour \\
Reversibility & $100 \%$ reversible \\
Air density & $1.38 \mathrm{~kg} / \mathrm{m}^{3}$ \\
\hline
\end{tabular}

point pressure. This is a pressure rise across the package, and therefore after accounting for the pressure loss through the silencers. Additionally, the package must achieve its specification at ambient temperature, with the associated increased blade tip-to-casing clearance needed to enable the fan to operate at elevated temperatures during a tunnel fire.

Although not explicit in the Parsons Brinckerhoff specification, the ventilation plant room's size dictated the overall size of the fan, transform, damper, and silencer package. Despite the constraint on the ventilation plant room size, it was necessary to retain the ability to undertake routine fan maintenance within the plant room's confines.

\section{Tunnel Ventilation Fan Conceptual Design}

Two fans, counter-rotating, are particularly effective when $100 \%$ reversibility is required. The reason is that the second fan removes the exit flow swirl from the first. This results in axial flow exiting the second stage and therefore an inherently more efficient aerodynamic solution than is possible with a single-stage fan. Simply changing both fans' rotation direction achieves reversibility. The counter-rotating twostage fans' inherent aerodynamic efficiency translates into achievable pressure, which is typically 2.5 times the pressure that one of the two fans operating in isolation can achieve. However, two fans counter-rotating result in unsteady flow from the first fan entering the second. This increases noise production in the second. Consequently, silencers must be correspondingly larger for a fixed acoustic specification.

When acoustic considerations make a two-stage counterrotating fan-based package potentially too large in a specific application, a second option available to the tunnel ventilation fan designer is to move beyond current mechanical limits for single-stage reversible fans. The choice of aluminium as the blade material limits today's tunnel ventilation fan technology. Aluminium enables the designer to design fans with a tip speed of up to $175 \mathrm{~m} / \mathrm{s}$. Within the context of the required specification, Table 1 , this would equate to a 2.24 metre diameter fan running at $1500 \mathrm{rpm}$. A reversible 2.24 metre fan running at $1500 \mathrm{rpm}$ has the potential to generate $3000 \mathrm{~Pa}$ pressure rise; however, operators would not normally consider this as the selection would result in the fan operating far from its peak aerodynamic efficiency. In effect, it would be impossible to achieve the target $70 \%$ minimum fan efficiency.

Despite the above reservation about fan efficiency, fan pressure rise increases in proportion to the ratio of fan diameter squared. As such, a $12 \%$ increase in fan diameter from 2.24 metres to 2.5 metres will increase fan pressure developing capability by $24 \%$, increasing potential pressure from $3000 \mathrm{~Pa}$ to $3700 \mathrm{~Pa}$. This increase in fan diameter would necessitate an increase in blade tip speed from $175 \mathrm{~m} / \mathrm{s}$ to $196 \mathrm{~m} / \mathrm{s}$. In practice, improving aluminium blade design could not increase in tip speed. Sheard et al. [12] presented fan blade mechanical design optimisation and described a computational based methodology for minimising blade stress for a given aerodynamic design point. In effect, Sheard et al. [12] maximised aerodynamic performance within the blade material's mechanical limits. Therefore, only moving away from aluminium to a higher strength-to-weight material, with titanium as the preferred choice within the aerospace industry, can achieve an additional increase in blade tip speed. Carbon fibre blades are not an option as a consequence of the EN 12101-3 high temperature emergency requirement.

Although a move from aluminium to titanium has the potential to achieve a higher pressure within a singlestage reversible fan, there is an acoustic consequence with running at an increased tip speed. A 2.50 metre diameter fan running at 1500 revolutions per minute will generate approximately $4 \mathrm{~dB}$ more noise than a 2.24 metre diameter fan running at the same speed. Consequently, silencers must be correspondingly larger for a fixed acoustic specification.

A third concept is to remain within the aluminum blades' mechanical limits, return to a lower speed two-stage fan, but this time using a single motor with an impeller on both ends. As the fan motor separates the two impellers, the solution is relatively quiet compared to either a two-stage counterrotating or high-speed single-stage solution.

The above results in three high pressure reversible tunnel ventilation fan concepts.

(1) A two-stage counter-rotating fan.

(2) A single-stage high speed fan.

(3) A two-stage double ended motor fan.

Each is a viable option, with its own strengths and weaknesses, Table 2 .

Although assessment of technical risk is subjective, we can, at least, broadly characterise the technical risks of each concept. The two-stage counter-rotating fan concept is a low technical risk, as it is the standard solution when pressure exceeds that which a single-stage can achieve. The concept has a good in-service reliability record.

The single-stage high speed fan concept is high technical risk, as it involves moving from a traditional tunnel ventilation fan blade material to a material which engineers usually associate with the aerospace industry. Although the move is not inevitably problematic, new supply chain development and the mechanical validation of titanium blades would be time consuming, with problems emerging during the mechanical validation process. The nature and extent of the 
TABLE 2: Relative merits of the three fan system concepts.

\begin{tabular}{lccc}
\hline & $\begin{array}{c}\text { Concept 1 } \\
\text { (Counter rotating) }\end{array}$ & $\begin{array}{c}\text { Concept 2 } \\
\text { (High speed) }\end{array}$ & $\begin{array}{c}\text { Concept 3 } \\
\text { (Double ended motor) }\end{array}$ \\
\hline Pressure & 2.5 & 2.25 & 1.8 \\
Peak efficiency & $+8 \%$ & $+2 \%$ & $+5 \%$ \\
Noise & $15 \mathrm{~dB}$ noisier & $10 \mathrm{~dB}$ noisier & $8 \mathrm{~dB}$ noisier \\
Cost & 2.0 a single fan & 2.5 a single fan & 2.0 a single fan \\
Size & 2.0 the length of a single fan & 1.1 the length of a single fan & 1.3 the length of single fan \\
Technical risk & Low & High & Medium \\
\hline
\end{tabular}

Note 1: All comparisons are relative to that of a single-stage fan of the same diameter.

Note 2: Peak efficiency is relative to that of a current state of the art single-stage reversible fan with a peak efficiency of $70 \%$.

mechanical design problems are difficult to quantify due to the application's novelty and therefore constitute a high technical risk.

The two-stage double ended motor option is a medium technical risk, as it remains within existing mechanical limits; however, as a consequence of the novel double ended configuration, will not fall within existing EN 12101-3 certification. EN 12101-3 certification of a range of double ended motor fans implicitly requires large fan high temperature testing in accordance with EN 12101-3 requirements. Large fan high temperature tests are challenging and therefore constitute a significant, but quantifiable technical risk.

3.1. Concept 1: Counter Rotating Fan. The authors estimated the aerodynamic performance of a two-stage counterrotating fan that will achieve the specification in Table 1 by scaling the smaller single-stage fans' performance using Daly's method [3], Figure 1. The selection is good, as a consequence of the required duty point falling close to the fan characteristic's peak efficiency point. The twostage counter-rotating configuration's inherent aerodynamic efficiency results in an efficiency that comfortably exceeds the specified $70 \%$ minimum.

3.2. Concept 2: High Speed Single-Stage Fan. The authors estimated the single-stage high speed fan's aerodynamic performance that will achieve the specification in Table 1 by scaling a lower speed fan's performance, Figure 2 . The selection is also good, as a consequence of the required duty point falling close to fan characteristic's peak efficiency point. The exit swirl from a single-stage results in a lower aerodynamic efficiency than that of the two-stage counterrotating selection. Consequently, the single-stage high speed fan has a lower predicted efficiency of $71 \%$. The uncertainty that we see with scaling fan performance data is typically no better than $\pm 1 \%$ and so a laboratory performance test would need to validate this fan selection's ability to achieve the minimum $70 \%$ efficiency.

3.3. Concept 3: Double Ended Fan. The authors estimated the two-stage double ended motor fan's aerodynamic performance that will achieve the specification in Table 1 by scaling the single-stage fan's performance, Figure 3 . The selection is also good, as a consequence of the required

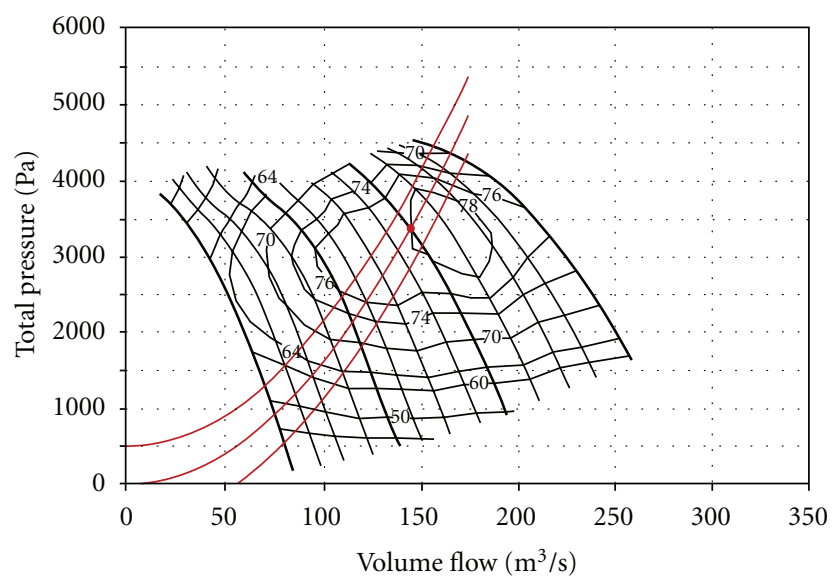

FIGURE 1: The characteristics of a 2.5 metre diameter, 6-pole twostage counter-rotating fan, with an estimated $78 \%$ efficiency at the Marmaray duty point.

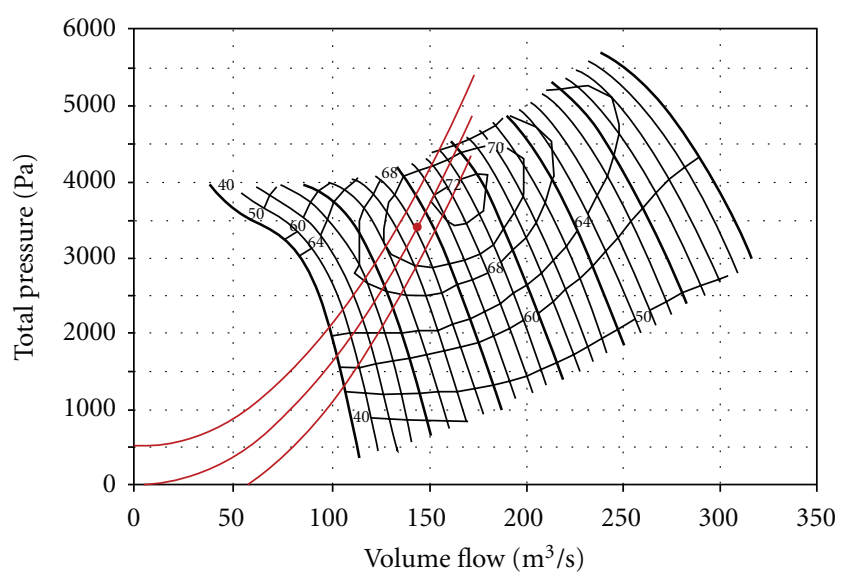

FIGURE 2: The characteristics of a 2.5 metre diameter, 4-pole singlestage high speed fan, with an estimated $71 \%$ efficiency at the Marmaray duty point.

duty point falling close to fan characteristic's peak efficiency point. The results include an assumption about the interstage flow straighteners' efficiency, with the assumption resulting in a predicted overall fan efficiency of $75 \%$. The authors estimated uncertainty with the interstage flow straighteners' 


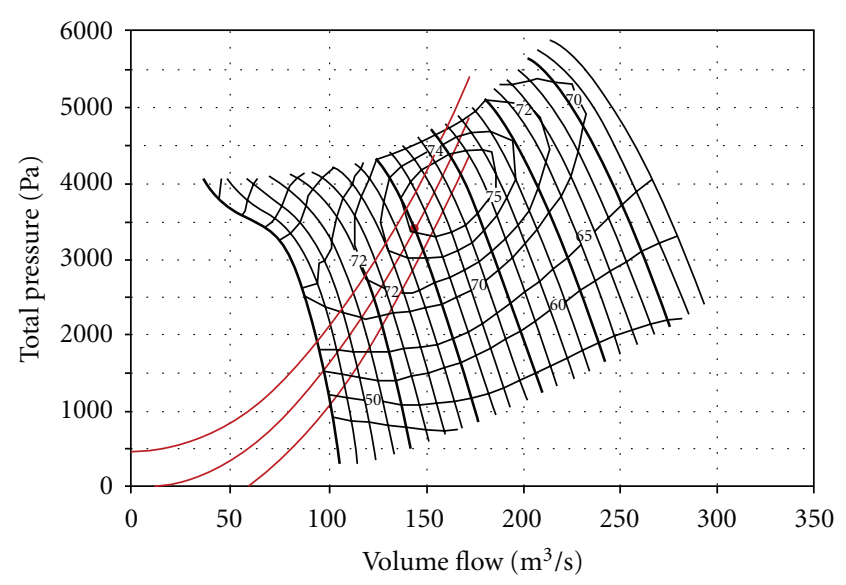

Figure 3: The characteristics of a 2.8 metre diameter, 6-pole twostage double ended motor fan, with an estimated $75 \%$ efficiency at the Marmaray duty point.

actual performance at 3\%, and consequently, a potential minimum $72 \%$ fan efficiency. As a consequence of the uncertainty in fan efficiency, a laboratory test is necessary to validate this selection.

3.4. Tunnel Ventilation Fan Concept. Operators can use any of the above mentioned three fan concepts as a basis for a tunnel ventilation system fan, transform, silencer and damper package. Sheard et al. [13] considered the relative merits of the three fan concepts and concluded that the package's capital and through-life cost based on any one of the three fan concepts was similar. However, the package volume was significantly smaller for a package based on the third fan concept.

Package size has a direct impact on the underground plant room's required size for tunnel ventilation installation, and consequently a direct impact on the plant room's cost. Because of the third fan concept's relatively small package size, a two-stage double ended motor fan is the most suitable for a high pressure reversible tunnel ventilation fan.

\section{Fan Design Realisation}

Mine ventilation applications have utilised two-stage double ended motor axial fans since the 1950's, Figure 4. Space is restricted in a mine environment, and hence the two-stage double ended motor concept has historically proven practical in mine ventilation systems. However, mine ventilation applications generally use the two-stage double ended motor fans as booster fans, which are therefore classically up to 1.6 metres in diameter and up to $100 \mathrm{~kW}$ power. Sheard et al. [13] observed that the Marmaray tunnel ventilation fan selection required a 2.8 metre fan with a $710 \mathrm{~kW}$ motor and therefore represented a significant product extension beyond the historic range of mine ventilation fans.

The mechanical challenge which the product range extension posed was primarily confined to the motor bearing arrangement. The impellers remained within historic limits and therefore did not present a mechanical challenge.

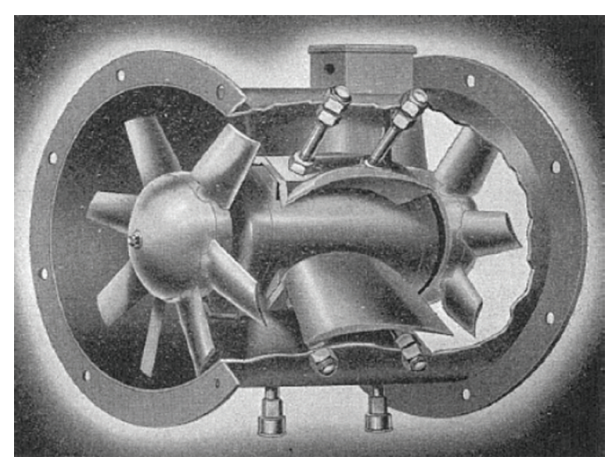

FIGURE 4: A 1959 vintage Woods of Colchester J-Range double-ended mine ventilation fan.

Reversible tunnel ventilation fans can operate in either direction. As such, aerodynamic loads associated with the pressure across the fan can also be in either direction. Second, the motor rotor and twin impeller also impose a significant gravitational load on the motor bearings. The loads imposed upon motor bearings require accommodation in both vertical and horizontal arrangements.

Historically, tunnel ventilation fan manufacturers have specified motors with deep-groove ball bearings. As fan power and size have increased, there has been a recent requirement to move to angular-contact bearings for vertical installations, as Sheard and Jones [14] describe. A move to single large motors with an impeller on each end increases bearing loads significantly beyond the deep-groove ball bearing's load carrying capability in horizontal application or an angular-contact ball bearing in vertical application.

The bearing arrangement which the authors adopted for horizontal application, Figure 5, utilised roller-bearings at each end of the motor shaft. The roller-bearings were free to float, with a single deep-groove ball bearing accommodating the axial load. The bearing arrangement which the authors adopted for vertical application, Figure 6, utilised a pair of deep-groove ball bearings to accommodate the gravitational and aerodynamic loads. The aerodynamic loads either added to or reduced the gravitational load, depending on the flow direction though the fan. The aerodynamic loads are significantly lower than the gravitational load, and consequently, although the vertical bearing load's magnitude changes as the fan changes from forward to reverse operation, it is always in the same direction. The authors completed the vertical bearing arrangement with a floating deep-groove ball bearing.

The tunnel ventilation system design drives the requirement to install tunnel ventilation fans either horizontally or vertically. The requirement has only minimal impact on the fans' aerodynamic performance and no impact on the fan impellers' mechanical design. However, the fan casing and motor mounting arrangement are significantly different for vertical or horizontal installation.

When installed horizontally, the preference is a foot mount motor arrangement, Figure 7, as it allows mechanical loads to pass though the casing and into the fan's mounting frame. Foot mounted motor design within tunnel ventilation 

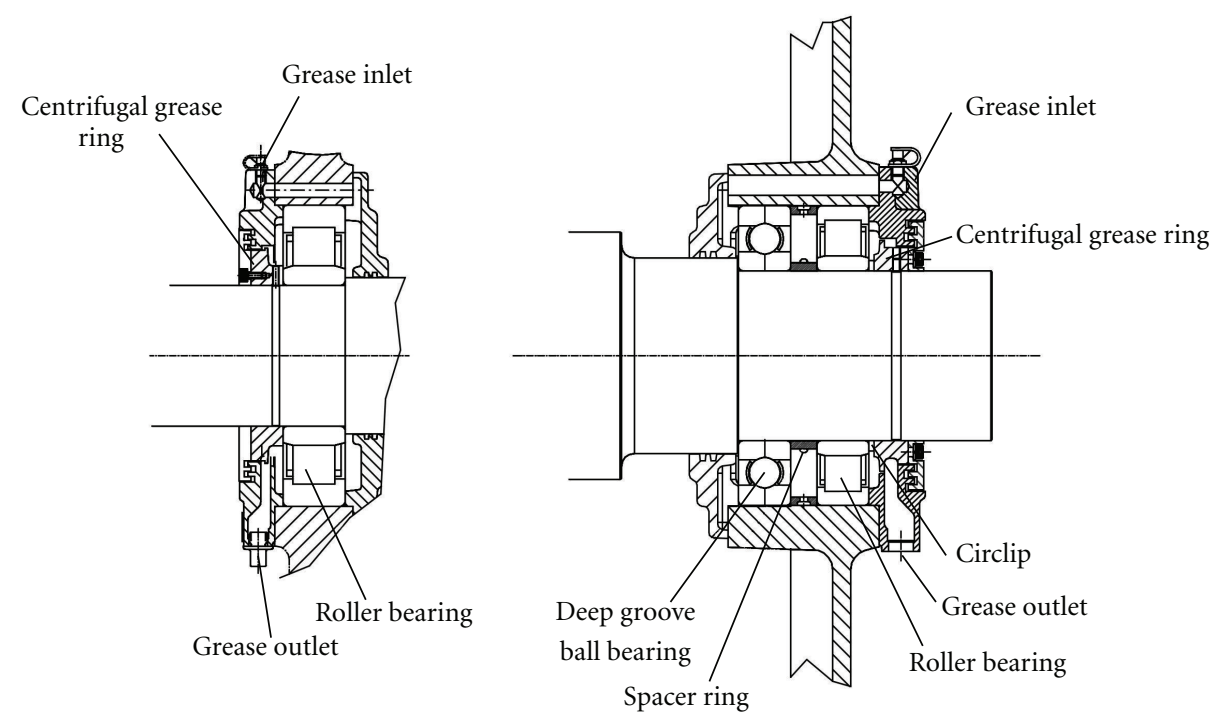

Figure 5: Fan motor bearing configuration for the horizontal two-stage double ended motor fan.

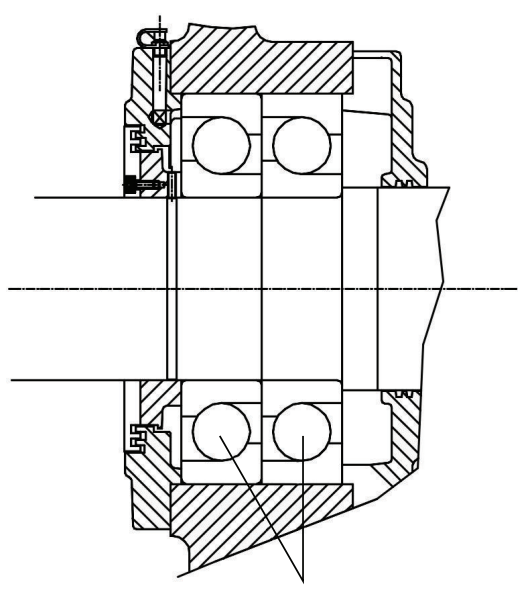

Deep groove ball bearings

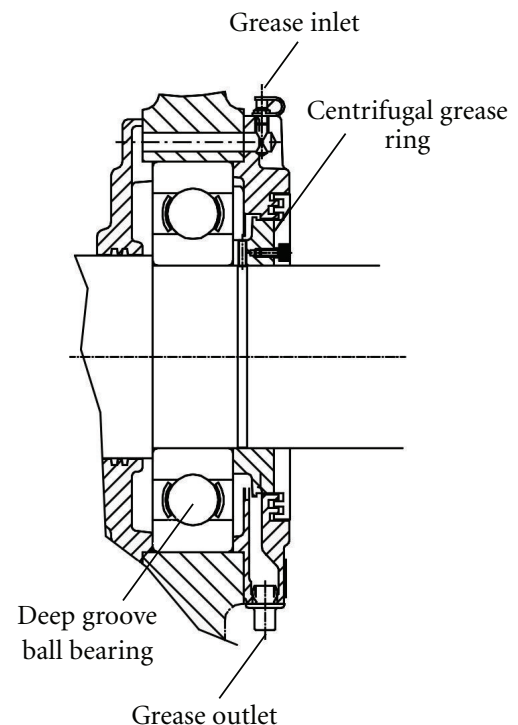

FIGURE 6: Fan motor bearing configuration for the vertical two-stage double ended motor fan.

fans is well established and consequently, a mechanically functional casing design is routine. Fan size and the twin impeller concept result in design for maintainability became the greater challenge. The Marmaray tunnel ventilation fan package location within a plant room restricted access for maintenance, and consequently, the team had to design the fan casing to facilitate maintenance within a confined environment, as Sheard et al. [13] describe. The casing design is split to allow casing removal in segments, leaving the motor and impellers accessible. Lifting point locations in the plant room and special tooling design for casing segment, impeller and motor removal were all considerations during the fan mechanical design.
The preference was a flange mounted motor arrangement when installing vertically, Figure 8 . The motor mounts inside a drum, with mechanical loads transferring though flowstraighteners to a heavy casing that in turn mounts onto a base-frame via four mounting arms. As with the horizontal casing design, the casing is segmented to allow maintenance access to the two impellers and the motor's top.

A requirement to fit combined deep-groove, roller, and angular-contact bearings, plus the requirement to include multiple casing split lines both had an implication for the two-stage double ended motor fans' EN 12101-3 certification. The certifying authority considers a change in bearing arrangement and casing split line inclusion as fundamental 


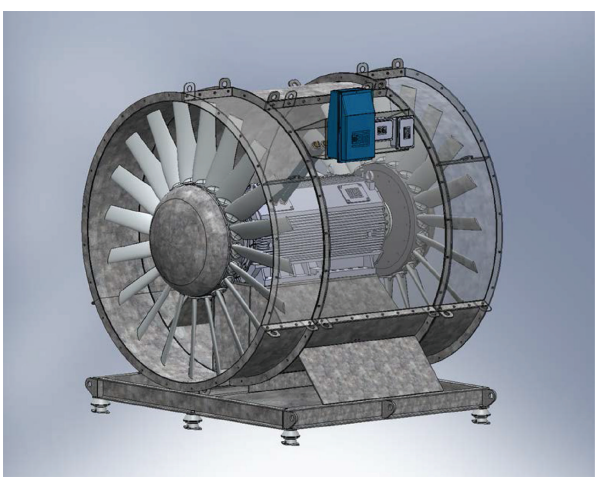

FIgURE 7: A computer-aided design model of the horizontal 2.8 metre two-stage double ended motor fan designed for the Marmaray project.

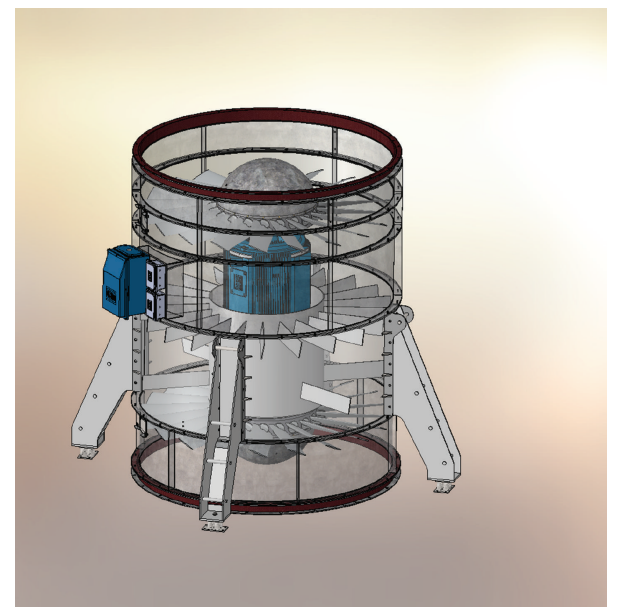

Figure 8: A computer-aided design model of the vertical 2.8 metre two-stage double ended motor fan designed for the Marmaray project.

changes that require validation via third-party independent testing. Sheard and Jones [15] describe this process.

4.1. Prototype Laboratory Performance. Following the Marmaray fan mechanical design completion, the authors built an $1800 \mathrm{~mm}$ scaled prototype of the full size design, Table 3. The authors tested the prototype in a ducted system in accordance with ISO 5801:2007 requirements [16]. They adopted Mattern et al's recommendations [17] for calculating the fan pressure rise. Experimental results were obtained with both impellers fitted and with one impeller fitted. Knowing the prototype's performance with both one and two impellers fitted enabled the authors to empirically establish the scaling rules which they needed to predict twin impeller fan aerodynamic performance from single impeller performance.

The agreement was good between the prototype's aerodynamic performance from the single impeller data when subject to the scaling rules and the performance data which the authors obtained from the prototype when testing with

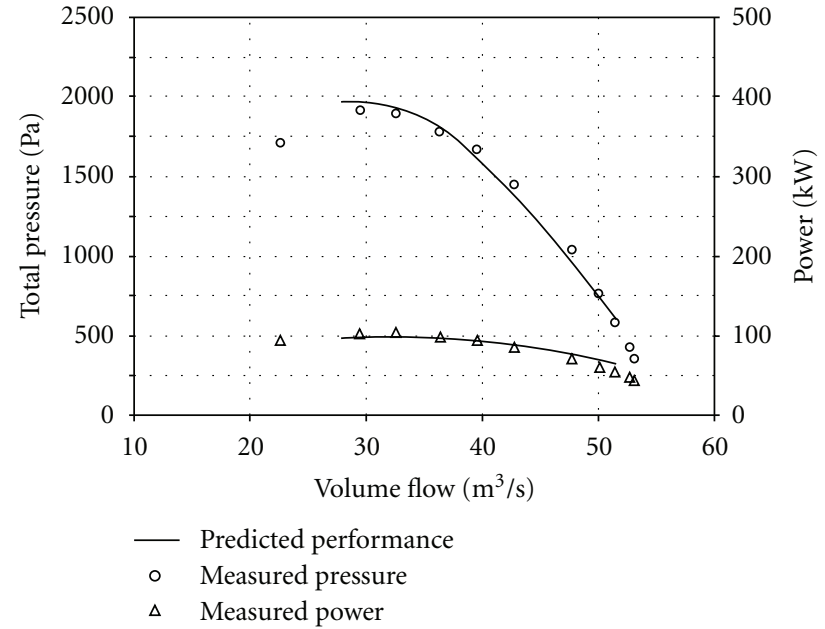

FIGURE 9: Aerodynamic performance of a 1.8 metre prototype twostage double ended motor fan.

TABle 3: Prototype and full size double ended motor tunnel ventilation fan specification.

\begin{tabular}{lcc}
\hline & Prototype fan & Full size fan \\
\hline Diameter (metres) & 1.8 & 2.8 \\
Hub ratio & 0.44 & 0.40 \\
Tip solidity & 0.5 & 0.5 \\
Blade number & 16 & 20 \\
Running speed (RPM) & 990 & 890 \\
Blade passing frequency (Hz) & 264 & 297 \\
\hline
\end{tabular}

both impellers, Figure 9. This gave confidence in both the accuracy and conservatism of the assumptions when deriving the scaling rules.

The authors measured the prototype's acoustic performance with both single and twin-impellers, Figure 10, in accordance with ISO 10302:1996 requirements [18] (equivalent to British Standard BS 848-2:2000). This enabled the authors to empirically establish the spectrum correction factors that they needed to predict twin impeller acoustic performance from single impeller performance.

Although the prototype fan had been manufactured with a casing arrangement that would facilitate the optimisation of the motor mounting arrangement and interstage flow straighteners, the authors considered the results for the "as designed" geometry good enough to make further optimisation unnecessary. The authors undertook some experimental work to establish the sensitivity of both aerodynamic and acoustic performance to those changes in geometry that might occur as a consequence of manufacturing tolerances. Additionally, the authors evaluated the impact of inlet flow distortion on both aerodynamic and acoustic performance. Following the experimental campaign, the authors deemed the mechanical design both aerodynamically and acoustically fit for purpose. This initiated the manufacture of the first production unit. 


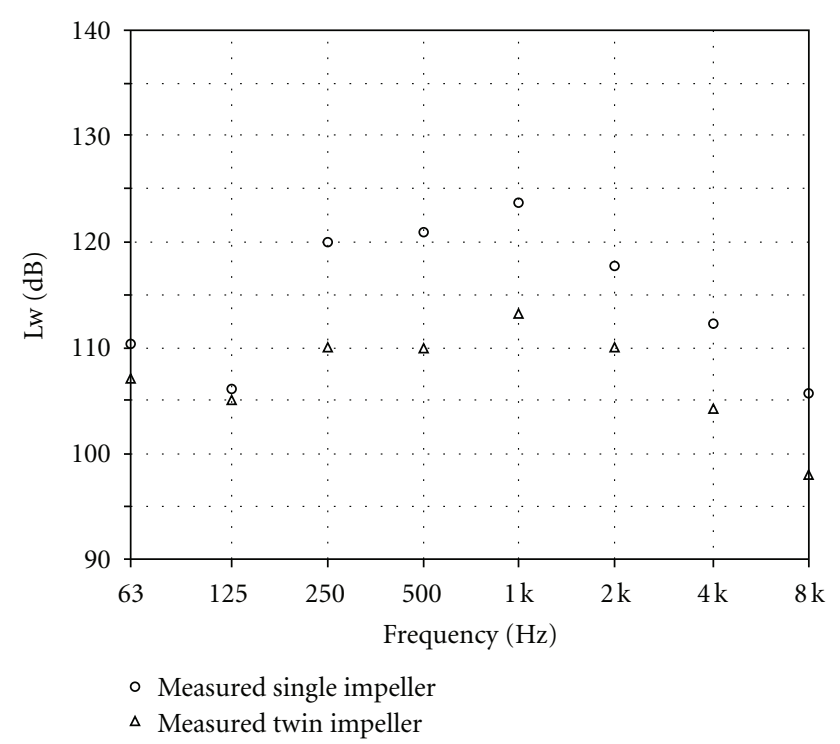

Figure 10: Acoustic performance of a 1.8 metre prototype twostage double ended motor fan, tested with one and two impellers fitted.

4.2. Package Performance. Laboratory testing of the prototype fan was a fan-only test which the authors used to verify the fan performance. Package performance verification necessitated the authors to test a production fan with production transforms, silencers, and dampers. The package size, Figure 11, necessitated an outdoor test which introduced some additional uncertainty into the measured aerodynamic and acoustic performance. Testing on a still day minimised the effects of cross-winds on measured aerodynamic performance and background noise. The authors again measured aerodynamic performance in accordance with ISO 5801 (2007) requirements [16] and acoustic performance in accordance with ISO 10302:1996 requirements [18].

The package's aerodynamic performance, Figure 12, was in good agreement with the scaled performance prediction. The experimental performance data exhibited a slightly steeper curve than the scaled data, indicating that the offdesign performance was not as well predicted as the design point performance. Given the assumptions when scaling the two-stage fan data from single-stage data, plus the assumptions regarding transition, silencer, and damper aerodynamic loss, the authors judged the correlation between scaled and experimentally measured performance as good.

Experimentally measured acoustic data for the full size fan also matched the predicted data well, Figure 13. There was some discrepancy between predicted and measured spectrum; however, the overall measured outlet noise level of $135 \mathrm{~dB}$ compared well with the predicted value of $136 \mathrm{~dB}$. The discrepancy in the low frequency band suggests that the spectrum correction factor obtained from the measurement on the prototype fan are not accurate, and therefore further refinement would be necessary to enable the designer to make a more accurate prediction of the acoustic spectrum of the twin impeller fans using the single-stage source

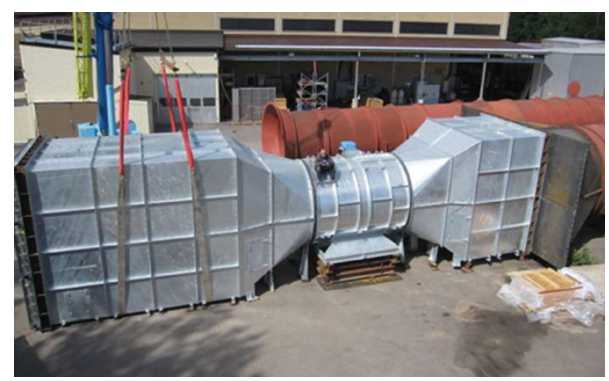

Figure 11: The first production Marmaray 2.8 metre two-stage double ended motor fan, transform, silencer, and damper package set up prior to its aerodynamic and acoustic test.

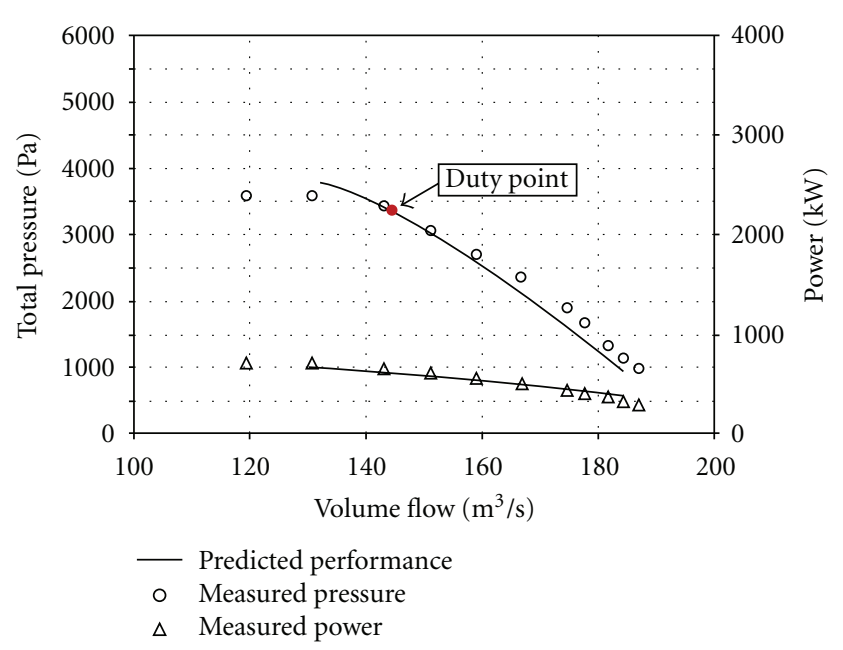

FIGURE 12: Predicted and measured Marmaray project package aerodynamic performance.

data. However, despite this reservation about the spectrum correction factors, the overall sound levels were predicted within $1 \mathrm{~dB}$ of the measured value. With more than $1 \mathrm{~dB}$ uncertainty in the measured value, the prediction of overall sound level may therefore be concluded to be correct within the uncertainty of the measurement.

The authors combined experimentally measured acoustic data for the full size fan, silencer insertion losses, and sys-tem effect to predict the ventilation package tunnel and atmospheric side sound level, Table 4 . The predicted ventilation package tunnel and atmospheric side sound levels were $81 \mathrm{~dB}$ and $82 \mathrm{~dB}$, respectively, which were within the $85 \mathrm{~dB}$ specification, and therefore the authors considered them as good.

4.3. EN 12101-3 Certification. Although the specification, Table 1, only required EN 12101-3 high temperature certification at $250^{\circ} \mathrm{C}$ for one hour, the preexisting Fläkt Woods EN $12101-3$ certification was at $300^{\circ} \mathrm{C}$ for two hours. Designing and testing at $300^{\circ} \mathrm{C}$ for two hours enabled the authors to extend the existing range certification. This required less testing and documentation than creating an entirely new $250^{\circ} \mathrm{C}$ test for a one hour range.

Within the European Union, it is a legal requirement for tunnel ventilation fans to comply with the Euro Norm 
TABLE 4: System acoustic calculation at the tunnel and atmospheric side.

\begin{tabular}{|c|c|c|c|c|c|c|c|c|c|}
\hline & & $63 \mathrm{~Hz}$ & $125 \mathrm{~Hz}$ & $250 \mathrm{~Hz}$ & $500 \mathrm{~Hz}$ & $1 \mathrm{KHz}$ & $2 \mathrm{KHz}$ & $4 \mathrm{KHz}$ & $8 \mathrm{KHz}$ \\
\hline \multicolumn{10}{|l|}{ Tunnel side } \\
\hline Fan LW & & 123 & 120 & 130 & 130 & 127 & 121 & 120 & 114 \\
\hline System losses & & 0 & 0 & 0 & 0 & 0 & 0 & 0 & 0 \\
\hline Room effect & & -3 & -5 & -7 & -9 & -10 & -11 & -11 & -12 \\
\hline Attenuator insertion loss & & -16 & -32 & -45 & -50 & -50 & -50 & -38 & -27 \\
\hline Resultant LwA (85 dBA spec) & 81 & 104 & 83 & 78 & 71 & 67 & 60 & 71 & 75 \\
\hline \multicolumn{10}{|l|}{ Atmospheric side } \\
\hline Fan LW & & 123 & 120 & 130 & 130 & 127 & 121 & 120 & 114 \\
\hline System losses & & -2 & -3 & -4 & -5 & -5 & -5 & -6 & -6 \\
\hline Atmos effect & & -14 & -14 & -14 & -13 & -13 & -13 & -13 & -13 \\
\hline Attenuator insertion loss & & -8 & -20 & -33 & -40 & -50 & -48 & -25 & -15 \\
\hline Resultant (85 dBA spec) & 82.3 & 99 & 83 & 79 & 72 & 59 & 55 & 76 & 80 \\
\hline
\end{tabular}

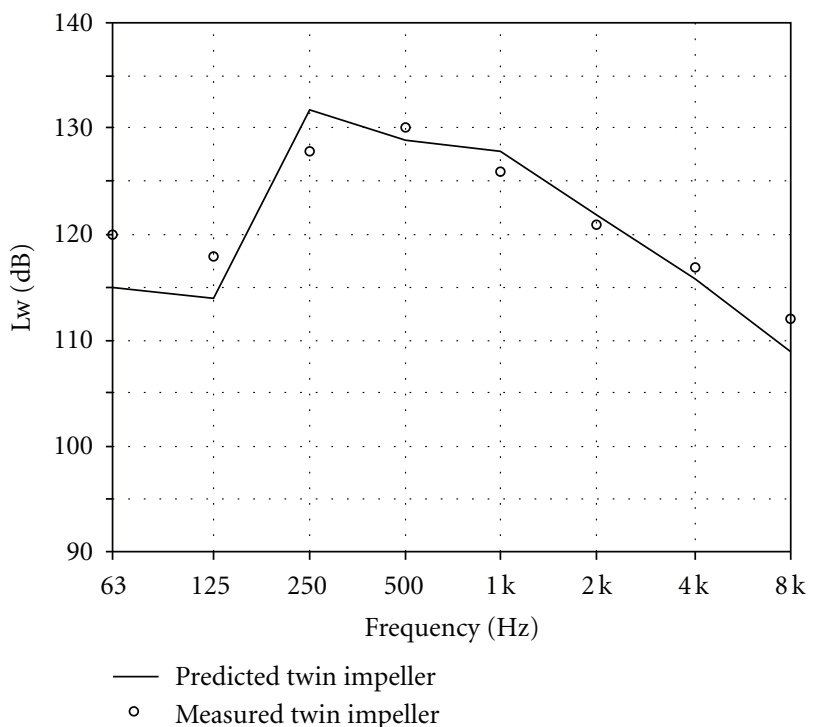

Figure 13: Predicted and measured Marmaray project package outlet acoustic performance.

EN 12101-3 requirements. The Marmaray project is part of Istanbul's infrastructure upgrade programme. The capital of Turkey, Istanbul, is not part of the European Union. As such, it is not a legal requirement for fans in the Marmaray project to comply with EN 12101-3 requirements. However, Turkey aspires to join the European Union and an aspect influencing the final decision is Turkey's ability to implement Euro Norms. This is why the tunnel ventilation fans in the Marmaray project complied with EN 12101-3.

The Euro Norm EN 12101-3 defines how to approve "powered smoke and heat control" fans. For the purpose of type approval, Sheard and Jones [15] observed that it is not necessary to test every fan size in a product range. Initially testing the following will significantly reduce testing:

(i) the fan with the most highly stressed impeller, and the fans with impellers in which the individual stress in any component, weld or fastening is the highest, as appropriate, if not the same;

(ii) fans with motors mounted in an enclosure which restricts the cooling; this is the fan with the smallest free area of the motor enclosure or the smallest section of exit or entry airway for cooling air;

(iii) at least two fan sizes at their highest rotational speed;

(iv) the fan with the smallest motor frame size to be used, except for fans where the impeller is not mounted on the motor shaft and the motors are out of the airstream in ambient air and heat transfer from the fan or the fan construction does not affect the motor's cooling;

(v) if the highest impeller stress levels are determined by geometric similarity conditions, sufficient sizes of fans to ensure that the impeller diameters of the range are from 0,80 to 1,26 of those tested;

(vi) if the highest impeller stress levels are determined by calculation, sufficient sizes of fans to ensure that the impeller diameters of the range are from 0,63 to 1,26 of those tested.

The Euro Norm EN 12101-3 was introduced in 2002, and has the full designation EN 12101-3:2002. The working group responsible for EN 12101-3:2002 has recently been drafting a revision that was planned for publication, and notification in the official journal of the European Union, by the end of 2012. Sheard and Jones [19] considered the changes between EN 12101-3:2002 to EN 12101-3:2012 and noted that the primary changes addressed factory production control (FPC) of motors and the approval of variable frequency drives. The date for release of the final draft revision has since been extended by nine months so that editorial changes can be made to satisfy the requirements of the forthcoming EC Construction Products Regulation which will replace the existing Construction Products Directive in mid 2013.

The potential impacts of a variable frequency drive on a three-phase motor's winding insulation and bearings are significant. That is why the 2012 revision provides information on the testing of fans which will operate with 
a variable frequency drive. To approve a fan for operation via a variable frequency drive at both ambient and at a high temperature, a test fan can be installed and operated with the electrical supply provided from a pulse width modulation (PWM) variable frequency drive. We can assume that a fan is able to withstand the same maximum peak to peak voltage values and voltage rise rate at the motor terminals in an installation as it did during the test, independent of the type or brand of PWM variable frequency drive that the operator uses. Alternatively, a fan that has only been approved from direct-on-line testing may be used with a PWM drive if it is installed with line chokes or filters and the motor power is suitably derated.

If an operator only intends to use a fan driven by a PWM variable frequency drive at ambient temperature, then a fan tested direct-on-line may be installed with a variable frequency drive, provided that the drive is by-passed during an emergency smoke and heat exhausting operation.

The fan manufacturer must always retain the overall control and shall have the necessary means to take responsibility for the conformity of the product with its declared performance(s). However, the 2012 EN 12101-3 revision provides detailed information on how ongoing compliance of a motor for installation within a smoke control fan can be demonstrated by a motor manufacturer's factory production control (FPC) system, evaluated by an independent body according to the following rules.

(1) The motor manufacturer selects a body for inspection and, if necessary, a body for tests.

(2) Only the selected inspection body performs the motor manufacturer's factory production control assessment and writes an inspection report in English.

(3) The motor manufacturer can then transmit the inspection report to all fan manufacturer customers, or directly to a customer's notified test authority for reasons of confidentiality.

(4) If the motor manufacturer changes or wants to change some design element or construction, he or she must inform the selected test laboratory which will perform, if required by the rules indicated in the standard, additional test(s). Then the motor manufacturer provides the test report (also written in English) to the inspection body so that it can note these change in the inspection report.

The fan manufacturer shall also have documented procedures which specify how to deal with noncomplying products, corrective actions and the handling, storage, and packaging of products (with suitable storage areas preventing damage or deterioration). The 2012 EN 12101-3 revision then emphasises that the fan manufacturer's factory production control system must address the EN 12101-3 product specific requirements, in effect introducing an EN 121013:2012 specific factory production control system. Tables provide details of materials and parameters that must be checked and information which shall be recorded. Guidance is provided for independent Notified Body assessors on what is required from an initial factory and FPC inspection.
Additional guidance is provided on requirements for the continuous surveillance of a suitable factory production control system.

As part of the Marmaray project, the authors' high temperature tested a 2.8 metre diameter tunnel ventilation fan with a variable speed drive at $300^{\circ} \mathrm{C}$ for two hours in accordance with the EN 12101-3 2012 revision requirements. To the best of the authors' knowledge, this 2.8 metre diameter fan is the largest diameter fan that anyone has tested in accordance with EN 12101-3 requirements. Sheard and Jones [14] reported a $1,050 \mathrm{~kW}$ fan as the highest power fan tested in accordance with EN 12101-3:2002 requirements. The authors tested that fan with a variable speed drive, and included a $1,050 \mathrm{~kW}$ motor from a motor manufacturer with a factory production control system. That test is also compliant with the 2012 version requirements of EN 12101-3.

The authors combined the 2.8 metre Marmaray project tunnel ventilation fan high temperature test with other high temperature tests which Sheard and Jones [15] previously undertook to certify a range of two-stage double ended motor fans.

\section{Conclusions}

The current state of the art in reversible industrial fan design limits the maximum pressure rise that an operator can practically achieve in a single reversible fan stage to $2000 \mathrm{~Pa}$. The reversibility requirement results in the necessity for symmetrical fan blade aerofoil sections. Also, guide vanes must be reduced to flow-straighteners if the fan is to produce the same flow and pressure in both directions. It is necessary for tunnel ventilation fans to produce the same flow and pressure in both supply and extract modes to enable the tunnel ventilation fans to accommodate the varied requirements for routine ventilation and to keep escape routes clear in the event of a fire.

As tunnels become longer and deeper, the pressure drop that occurs with the flow necessary to ventilate the tunnel can rise above the $2000 \mathrm{~Pa}$ limit of a current state of the art single reversible fan stage. In such cases, the traditional solution is to offer a two-stage fan with counter-rotating stages. A disadvantage of the two-stage counter-rotating fan is that it produces $15 \mathrm{~dB}$ more noise than one of the fans operating in isolation. Consequently, silencers must be larger for the same overall acoustic emissions at the silencer inlet and outlet.

In a situation where minimum overall fan, transform, silencer and damper package size is desirable, the two-stage counter rotating fan may not be the optimum fan concept. In such circumstances, the tunnel ventilation fan designer has two further fan concepts available. These include a highspeed single-stage fan or a two-stage double ended motor fan. Each represents a valid technical solution and has the potential to achieve a specified duty point. The three fan concepts are as follows:

(i) two-stage counter-rotating fan;

(ii) single-stage high speed fan;

(iii) two-stage double ended motor fan. 
The two-stage double ended motor fan concept resulted in the minimum package size, and so was chosen by the authors as the preferred concept. The authors primarily encountered two mechanical design challenges regarding the two-stage double ended motor fan. First, there was the issue of whether the motor bearing system design could accommodate the imposed aerodynamic and gravitational loads in both horizontal and vertical configurations. Second was the issue of designing a casing that operators could dismantle within a plant room's confines where engineers installed the fans and their associated package.

Having successfully addressed the mechanical design challenges, the authors measured the prototype fan's aerodynamic and acoustic performance. They them measured the full size package aerodynamic performance and full fan acoustic performance. Both aerodynamic and acoustic results were in good agreement with the original performance prediction scaled from single-stage fan data. Mechanical validation ended with a successful $300^{\circ} \mathrm{C}$ test for two hours of the full size fan, in accordance with EN 121013:2012 requirements.

\section{References}

[1] A. G. Sheard and A. Corsini, "The mechanical impact of aerodynamic stall on tunnel ventilation fans," International Journal of Rotating Machinery, vol. 2012, Article ID 402763, 12 pages, 2012.

[2] R. A. Wallis, Axial Flow Fans: Design and Practice, George Newnes Ltd., London, UK, 1961.

[3] B. B. Daly, Woods Practical Guide to Fan Engineering, Woods of Colchester Ltd., London, UK, 1985.

[4] J. Vad, "Incorporation of forward blade sweep in the non-free vortex design method of axial flow turbomachinery rotors," Periodica Polytechnica, Mechanical Engineering, vol. 45, no. 2, pp. 217-237, 2001.

[5] A. Corsini, F. Rispoli, J. Vad, and F. Bencze, "Non-free vortex flow effects in an axial flow rotor," Periodica Polytechnica, Mechanical Engineering, vol. 45, no. 2, pp. 201-216, 2001.

[6] K. Y. Lee, Y. S. Choi, Y. L. Kim, and J. H. Yun, "Design of axial fan using inverse design method," Journal of Mechanical Science and Technology, vol. 22, no. 10, pp. 1883-1888, 2008.

[7] K. Daneshkhah and A. G. Sheard, "A parametric study of reversible Jet-Fan blades' aerodynamic performance," Journal of Engineering for Gas Turbines and Power. In press.

[8] J. H. Horlock and J. D. Denton, "A review of some early design practice using computational fluid dynamics and a current perspective," Journal of Turbomachinery, vol. 127, no. 1, pp. 513, 2005.

[9] D. Borello, A. Corsini, F. Rispoli, and A. G. Sheard, "Investigation on the unsteady aerodynamics of an industrial fan," in Proceedings of the International Conference on Fan Noise, Technology, and Numerical Methods (Fan '12), pp. 18-20, Senlis, France, April 2012.

[10] M. J. Pratt, "Virtual prototypes and product models in mechanical engineering," in Proceedings of the IFIP WG 5.10 on Virtual Environments and their Applications and Virtual Prototyping, pp. 113-128, 1994.

[11] U. Jasnoch, H. Kress, and J. Rix, "Towards a virtual prototyping environment," in Proceedings of the IFIP WG 5. 10 on Virtual Environments and their Applications and Virtual Prototyping, pp. 173-183, 1994.
[12] A. G. Sheard, A. Corsini, S. Minotti, and F. Sciulli, "The role of computational methods in the development of an aero-acoustic design methodology: application in a family of large industrial fans," in Proceedings of the 14th International Conference on Modelling Fluid Flow Technologies, pp. 71-79, Budapest, Hungary, September 2009.

[13] A. G. Sheard, K. Daneshkhah, and A. Corsini, "Fan conceptual design as applied to the marmaray tunnel ventilation system," in Proceedings of the 58th American Society of Mechanical Engineers Gas Turbine and Aeroengine Congress, Paper No. GT2013-94548, San Antonio, Tex, USA, June.

[14] A. G. Sheard and N. M. Jones, "The development of a fan range to meet increasingly demanding safety criteria inside tunnels," in Proceedings of the 14th Australasian Tunnelling Conference: Development of Underground Space, pp. 305-318, Auckland, New Zealand, March 2011.

[15] A. G. Sheard and N. M. Jones, "Powered smoke and heat exhaust ventilators: the impact of EN, 12101-3 and ISO, 21927-3," Tunnelling and Underground Space Technology, vol. 28, pp. 174-182, 2012.

[16] ISO 5801, Industrial Fans-Performance Testing Using Standardized Airways, 2007.

[17] P. Mattern, S. Sieber, D. Cantrak, F. Frohlig, Ş Caglar, and M. Gabi, "Investigations on the swirl flow caused by axial fansa contribution to the revision of ISO 5801," in Proceedings of the International Conference on Fan Noise, Technology, and Numerical Methods (Fan '12), Senlis, France, April 2012.

[18] ISO 10302, Fans for General Purposes. Methods of Noise Testing. Airborne Noise Emitted by Small Air-moving Devices, 1996.

[19] A. G. Sheard and N. M. Jones, "An initial assessment of the changes that will appear in a forthcoming (2012) revision of EN 12101-3," in Proceedings of the International Conference on Fan Noise, Technology, and Numerical Methods (Fan '12), Senlis, France, April 2012. 

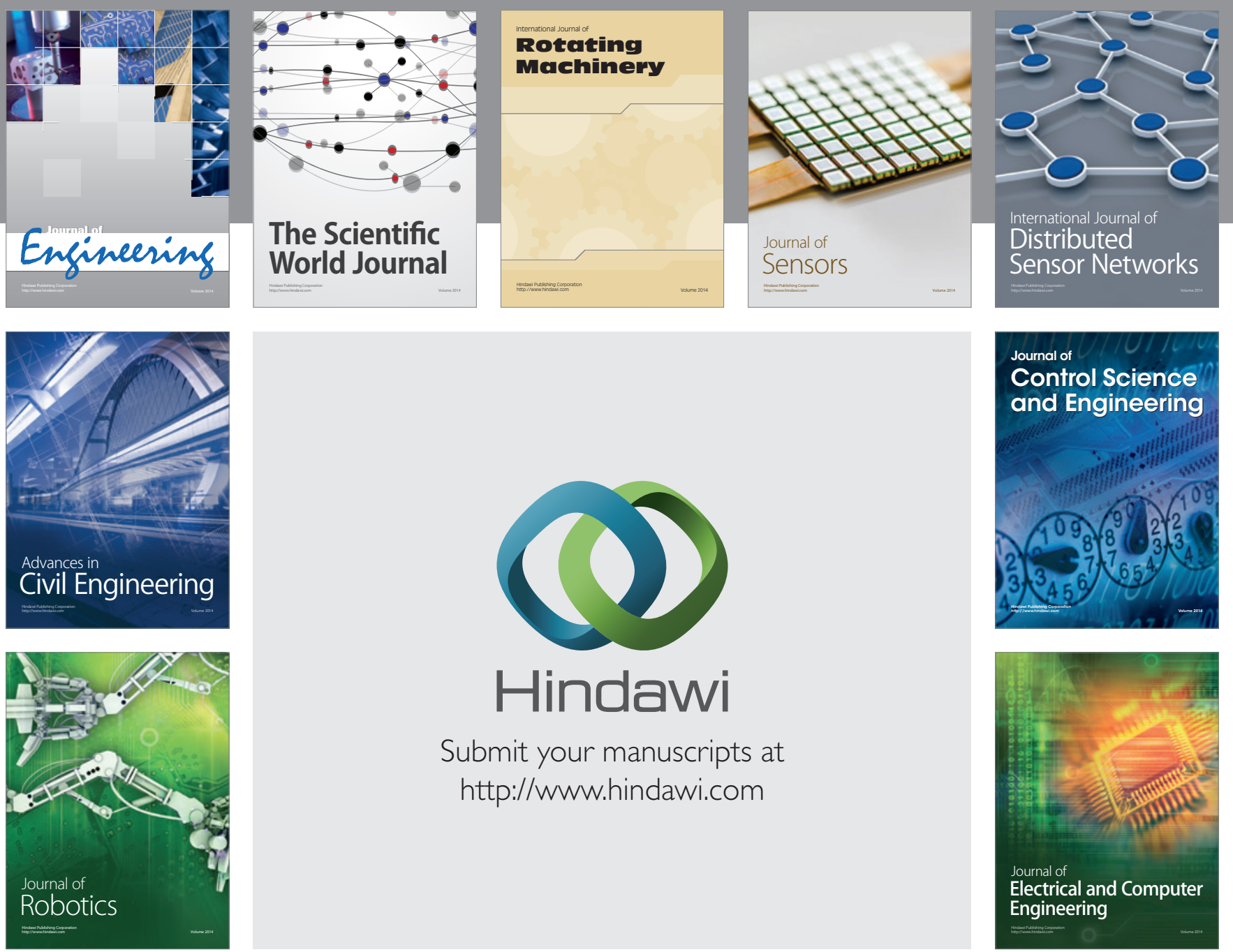

Submit your manuscripts at

http://www.hindawi.com
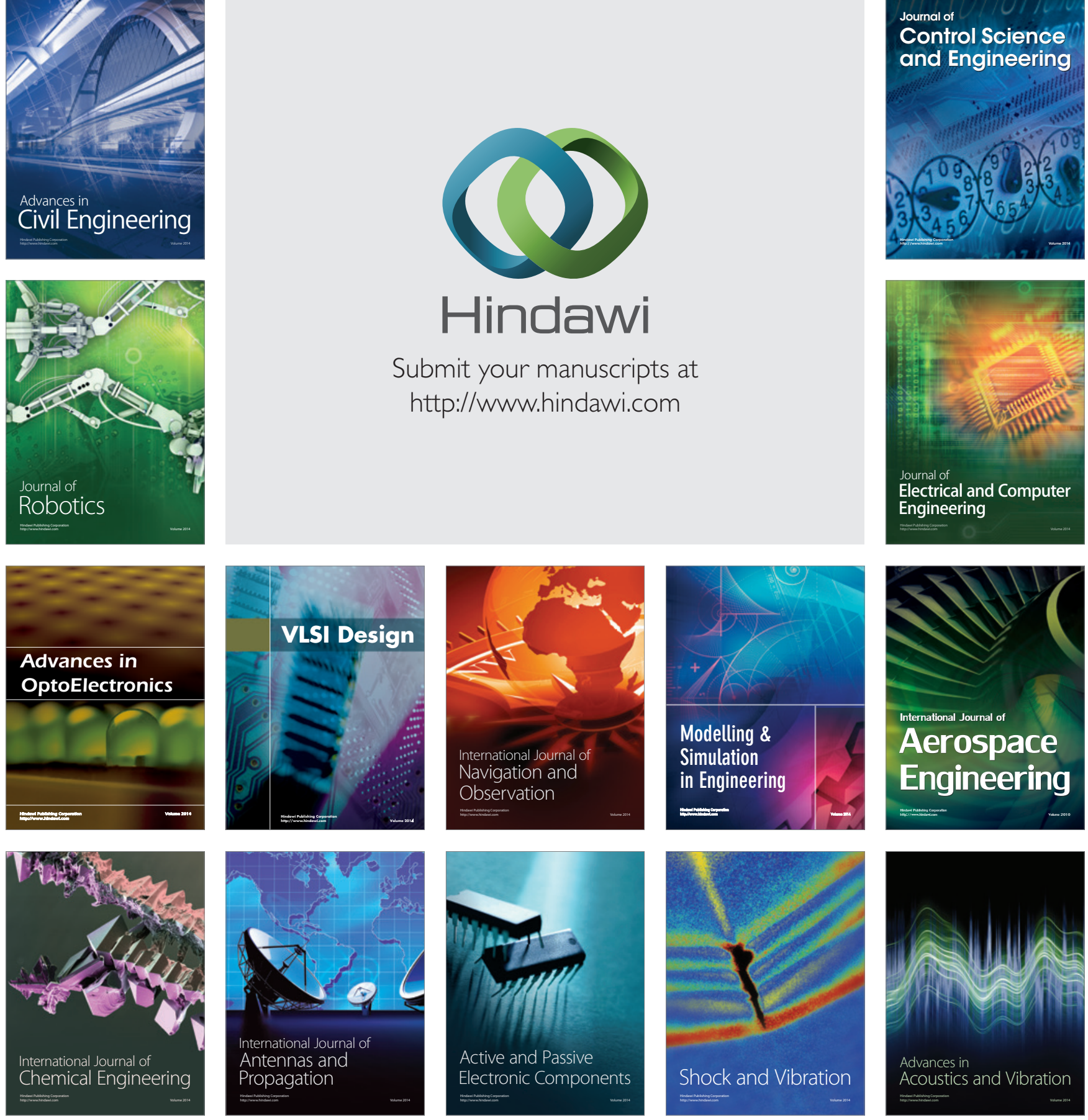